\title{
Malaria and Insecticide-Treated Net (ITN) Utilization among Orphans and Vulnerable Children in Nigeria
}

\author{
Oyetunde T. Oyeyemi1', Kehinde M. Akinseye², Iyanuoluwa I. Odewuyi², Rashidat O. Olayinka², \\ Oluwasegun E. Ajibawo², Imoleayo A. Ogunleye², Ifeoluwa I. Oyeyemi \\ 1 Department of Biological Sciences, University of Medical Sciences, Ondo, Ondo State, Nigeria \\ 2 Department of Biology, Adeyemi College of Education, Ondo, Ondo State, Nigeria
}

\section{CORRESPONDENCE \\ Oyetunde T. Oyeyemi University of Medical Sciences Laje Road, Ondo, Nigeria Tel: +2348163546787 E-mail: zootund@yahoo.com, ooyeyemi@unimed.edu.ng}

\section{ARTICLE HISTORY}

Received: February 17, 2021

Accepted: March 1, 2021
Kehinde M. Akinseye - P.M.B. 520, Ondo State Nigeria. Tel: +234 813012 5529, E-mail: support@ aceondo.edu.ng

lyanuoluwa I. Odewuyi • P.M.B. 520, Ondo State Nigeria. Tel: +234 813012 5529, E-mail: support@ aceondo.edu.ng

Rashidat O. Olayinka • P.M.B. 520, Ondo State Nigeria. Tel: +234 813012 5529, E-mail: support@ aceondo.edu.ng

Oluwasegun E. Ajibawo - P.M.B. 520, Ondo State Nigeria. Tel: +234 813012 5529, E-mail: support@ aceondo.edu.ng

Imoleayo A. Ogunleye • P.M.B. 520, Ondo State Nigeria. Tel: +234 813012 5529, E-mail: support@ aceondo.edu.ng

Ifeoluwa I. Oyeyemi: University of Medical Sciences Laje Road, Ondo, Nigeria Tel: +234 816354 6787,

E-mail: ioyeyemi@unimed.edu.ng

\begin{abstract}
Background: The lack of empirical data on the malaria status of orphans and vulnerable children (OVC), access to long-lasting insecticide-treated nets (LLINS), and knowledge about the disease can hamper the development of effective policies and programs to address their malaria-related needs. Aim: The aim of this study was to evaluate knowledge of malaria transmission and utilization of LLINs among OVC in Ondo metropolis, Nigeria. Materials and Methods: A cross-sectional study was conducted in Ondo City, Ondo State, Nigeria, between January and March 2018. The study was carried out among 66 OVC (age 5-19 years) using questionnaires. Information on socio-demography, LLIN utilization, knowledge and risks of malaria transmission among OVC was sought. Results: The use of LLINs (80.9\%) among OVC was significantly higher than the use of insecticide spray (6.1\%) and mosquito coils $(12.1 \%)(p<0.0001)$. Knowledge about malaria transmission was relatively high, and the majority of children (60.6\%) believed malaria is mostly transmitted during the dry season. Fewer children (21.2\%) had a history of malaria in the last 3 months. Conclusions: The risk of malaria transmission was low among OVC. Continuous accessibility of orphanage homes to LLINs should be sustained to prevent malaria transmission among OVC.
\end{abstract}

Keywords: malaria, prevention, knowledge, long-lasting insecticide-treated nets, vulnerable children

\section{INTRODUCTION}

Malaria continues to be a major public health threat in Nigeria, especially in pregnant women and children. It contributes to increased poverty, accounting for annual losses of up to $\$ 12$ billion in sub-Saharan African countries in the last decade. ${ }^{1}$ It was estimated that a death associated with pediatric malaria occurs every 45 seconds in Africa. ${ }^{2}$ It accounts for one million deaths per year, $60 \%$ of outpatient visits, $30 \%$ of hospitalizations, and $20-25 \%$ of infant and child deaths. ${ }^{3,4}$ 
Malaria-associated burden in children includes anemia and neurological disabilities in survivors of severe cases. ${ }^{5}$ The spread of malaria is not yet contained in many sub-Saharan African countries due to the emergence and spread of drug-resistant malaria parasites and insect-resistant mosquitos. ${ }^{6}$ The use of long-lasting insecticide-treated nets (LLINs) to prevent the transmission of malaria parasites is therefore widely advocated. However, transmission of malaria has become unabated in some high-risk zones due to the limited coverage of LLINs in the areas. ${ }^{7}$ Problems such as heat, cost, and size of nets have been identified to have great implications on LLIN utilization and control of malaria.

There has been a continuous rise in the number of orphans and vulnerable children (OVC) in Nigeria and other sub-Saharan African countries. This number has increased by more than 50 percent in recent times, and it is often caused by poverty, conflict, and gender inequality. ${ }^{8}$ Despite the fact that malaria is poverty-associated, and the country has one of the highest burdens of orphans in the world, the lack of empirical data on their malaria status, access to LLINs, and knowledge about the disease can hamper the development of effective policies and programs to address malaria-related needs of orphanages in the country. Therefore, the aim of this study was to evaluate knowledge of malaria transmission and LLIN utilization among OVC in Ondo metropolis. The study was conducted in Ondo City, one of the major cities in Ondo State, with a population of about 360,000 , located at longitude $7.09^{\circ} \mathrm{N}$ and latitude $4.80^{\circ} \mathrm{E}$. Ondo City is a center of commerce for the surrounding southwestern towns and one of the largest producers of cocoa in Nigeria. Like many other cities in the region, Ondo City suffers from the lack of some basic amenities. Importantly, there are no good drainage systems in many parts of the city, which often times results in flooding during the peak of rainy season. Stagnant water in various canals serves as good breeding sites for mosquito vectors which transmit malaria parasites and other tropical infections.

\section{MATERIALS AND METHODS}

We carried out a descriptive cross-sectional study. Participants included OVC aged between 5 and 19 years, recruited from three registered functional orphanages in Ondo City. The orphanages were selected based on accessibility and co-operation of the caregivers. A convenience nonrandomized sampling technique was adopted, and because we envisioned a low number of children in each orphanage, we recruited all the children who consented to the study. Overall, 66 individuals who completed all the items in the questionnaires were used for our analysis. Structured questionnaires based on thematic areas were tested before use. Information on LLIN utilization, knowledge, and risks of malaria transmission among OVC was sought. The questionnaires were administered by members of the research team in English or Yoruba, which are the predominant spoken languages of the included children.

Ethical approval was obtained from the University of Medical Sciences/Teaching Hospital Research Ethics Committee. Individual informed consent was obtained from all participants after prior consent from the caregivers. For very young children, information was sourced through the help of their caregivers. Those who were able to respond meaningfully to questions were recruited for the study, while children who could not read were helped by the caregivers to answer the questionnaires.

Data obtained was entered in Microsoft Excel spreadsheets and checked for accuracy. The data was then transferred into SPSS version 23 (IBM Corp. Released 2015. IBM SPSS Statistics for Windows, Version 23.0. Armonk, NY: IBM Corp.) for analysis. Chi-square and Fisher's exact tests were used to test for significant differences in variables related to LLIN usage, malaria transmission knowledge/ risk of malaria, and responses in different categories. A p value less than 0.05 was considered statistically significant.

\section{RESULTS}

The age of the study participants ranged from 5 to 19 years. The use of LLINs (80.3\%) for preventing mosquito bites was significantly higher than other methods, which included insecticide spray (6.1\%), use of mosquito coils $(12.1 \%)$, and wearing of protective clothing $(1.5 \%)(\mathrm{p}=$ 0.0001 ). The proportion of OVC who presently use LLINs (93.9\%) was also significantly higher than those who did not $(6.1 \%)(p=0.0001)$. A higher percentage of children got the LLINs for free $(89.4 \%)$ compared to those for whom the LLINs were bought by the caregivers or guardians $(10.6 \%)(\mathrm{p}=0.0001)$ (Table 1$)$. A significantly higher proportion of OVC had nobody to teach them how to hang the nets $(40.9 \%)$. There was no significant difference in the frequency of sleeping under LLINs per week: 1-3 times (28.8\%), 4-6 times (21.2\%), and 7 times (30.3\%) (p $=0.524)$. The results showed that $36.4 \%$ of the OVC did not share LLINs with others, while $25.8 \%$ and $37.9 \%$ of the OVC shared the LLINs with 1 other person and 2 or more other persons, respectively $(\mathrm{p}=0.280)$ (Table 1$)$.

A significantly higher proportion of children (65.2\%) believed that malaria is transmitted by the female Anoph- 
TABLE 1. Mosquito prevention and the use of long-lasting insecticide-treated nets

\begin{tabular}{|c|c|c|c|c|}
\hline Variables & Response & Number & Proportion (\%) & $p$ value \\
\hline \multirow[t]{4}{*}{ Prevention of mosquito } & Treated bed net & 53 & 80.3 & 0.0001 \\
\hline & Insecticide spray & 4 & 6.1 & \\
\hline & Mosquito coil & 8 & 12.1 & \\
\hline & Wearing of protective clothing & 1 & 1.5 & \\
\hline \multirow[t]{2}{*}{ Current usage of LLIN } & Yes & 62 & 93.9 & 0.0001 \\
\hline & No & 4 & 6.1 & \\
\hline \multirow[t]{4}{*}{ Quantity of LLIN } & One & 8 & 12.1 & 0.040 \\
\hline & Two & 15 & 22.7 & \\
\hline & Three & 18 & 27.3 & \\
\hline & Four or more & 25 & 37.9 & \\
\hline \multirow[t]{2}{*}{ Accessibility to LLIN } & Given free & 59 & 89.4 & 0.0001 \\
\hline & Bought & 7 & 10.6 & \\
\hline \multirow[t]{2}{*}{ Taught hanging of LLIN } & Yes & 41 & 62.1 & 0.049 \\
\hline & No & 25 & 37.9 & \\
\hline \multirow[t]{5}{*}{ Personnel who showed hanging of LLIN } & Government agency officials & 18 & 27.3 & 0.0001 \\
\hline & Doctor/nurse/health workers & 6 & 9.1 & \\
\hline & Members of homes & 14 & 21.2 & \\
\hline & Nobody & 27 & 40.9 & \\
\hline & Others & 1 & 1.5 & \\
\hline \multirow[t]{4}{*}{ Frequency of sleeping in LLIN/week } & $1-3$ times & 19 & 28.8 & 0.524 \\
\hline & 4-6 times & 14 & 21.2 & \\
\hline & 7 times & 20 & 30.3 & \\
\hline & Not all & 13 & 19.7 & \\
\hline \multirow[t]{3}{*}{ Number of persons sharing a net } & I don't share with anybody & 24 & 36.4 & 0.280 \\
\hline & 1 other person & 17 & 25.8 & \\
\hline & 2 or more other persons & 25 & 37.9 & \\
\hline \multirow[t]{4}{*}{ Length of time LLIN is being used } & $<6$ months & 43 & 65.2 & 0.0001 \\
\hline & 6-12 months & 7 & 10.6 & \\
\hline & $>12$ months & 4 & 6.1 & \\
\hline & I don't know & 12 & 18.2 & \\
\hline
\end{tabular}

eles mosquito ( $\mathrm{p}=0.0001)$. The response regarding the period of transmission for malaria also varied significantly, as $60.6 \%, 18.2 \%$, and $21.2 \%$ of the children believed malaria is transmitted in the dry season, wet season, and all seasons, respectively ( $p=0.0001)$. Almost all children $(97.0 \%)$ believed that mosquitos mostly bite during the night. A significantly higher proportion (75.8\%) of the study participants believed children represent a higher risk group for contacting malaria (Table 2). A significantly higher proportion of children (66.7\%) had no history of fever compared with those who reported a history of fever in the last 3 months $(21.2 \%)(p=0.0001)$. Also, a higher proportion of the OVC had not been diagnosed with malaria compared to $1.5-15.2 \%$ of the children who had been previously diagnosed with malaria one or more time in the last 6 months $(\mathrm{p}=0.0001)$. A higher number of children were treated for malaria in private clinics $(34.8 \%)$ compared to public clinics (28.8\%) (Table 2). A significantly higher pro- portion of study participants ( $81.8 \%)$ believed malaria is a public health problem.

\section{DISCUSSIONS}

Malaria is a public health menace in Nigeria, and efforts to curtail transmission are often focused on pregnant women and children aged 1 to 5 years. In recent years, the use of insecticide-treated mosquito nets has been one of the most widely implemented malaria control programs in Nigeria, and recent studies from Nigeria have shown an increase in the level of awareness, ownership, and usage of LLINs. ${ }^{9,10}$ Attention has been especially directed towards pregnant women and their newborns, the most vulnerable groups of malaria-associated burden. While other population strata have benefitted massively from campaigns against malaria transmission, it is important to evaluate the application of prevention campaigns in under-privileged population 
TABLE 2. Knowledge and risk of transmission of malaria among OVC

\begin{tabular}{|c|c|c|c|c|c|}
\hline Categories & Variables & Response & Number & Proportion (\%) & $p$ value \\
\hline \multirow[t]{16}{*}{ Knowledge } & \multirow[t]{5}{*}{ Route of malaria transmission } & Female Anopheles mosquito & 43 & 65.2 & \multirow[t]{5}{*}{0.0001} \\
\hline & & $\begin{array}{l}\text { Physical contact with malaria } \\
\text { patients }\end{array}$ & 16 & 24.2 & \\
\hline & & Overworking & 2 & 3.0 & \\
\hline & & Exposure to sun & 2 & 3.0 & \\
\hline & & I don't know & 3 & 4.5 & \\
\hline & \multirow[t]{3}{*}{ Period of malaria transmission } & Dry & 40 & 60.6 & \multirow[t]{3}{*}{0.0001} \\
\hline & & Wet & 12 & 18.2 & \\
\hline & & All seasons & 14 & 21.2 & \\
\hline & \multirow{3}{*}{$\begin{array}{l}\text { Period of the day mosquito mosquito } \\
\text { will mostly bite }\end{array}$} & Day & 1 & 1.5 & \multirow[t]{3}{*}{0.0001} \\
\hline & & Night & 64 & 97.0 & \\
\hline & & Any & 1 & 1.5 & \\
\hline & \multirow[t]{5}{*}{ The at most risk group } & Children & 50 & 75.8 & \multirow[t]{5}{*}{0.0001} \\
\hline & & Adults & 8 & 12.1 & \\
\hline & & Pregnant women & 2 & 3.0 & \\
\hline & & Teenagers & 5 & 7.6 & \\
\hline & & Others & 1 & 1.5 & \\
\hline \multirow[t]{13}{*}{ Risk } & \multirow[t]{3}{*}{ History of fever in the last 3 months } & Yes & 14 & 21.2 & \multirow[t]{3}{*}{0.0001} \\
\hline & & No & 44 & 66.7 & \\
\hline & & I don't know & 8 & 12.1 & \\
\hline & \multirow{5}{*}{$\begin{array}{l}\text { Frequency of malaria diagnosis in the last } \\
6 \text { months }\end{array}$} & Never & 42 & 63.6 & \multirow[t]{5}{*}{0.0001} \\
\hline & & 1 time & 10 & 15.2 & \\
\hline & & 2 times & 7 & 10.6 & \\
\hline & & 3 times & 1 & 1.5 & \\
\hline & & 4 times or more & 6 & 9.1 & \\
\hline & \multirow[t]{2}{*}{ Malaria prevention should be prioritized } & Yes & 54 & 81.8 & \multirow[t]{2}{*}{0.0001} \\
\hline & & No & 12 & 18.2 & \\
\hline & \multirow[t]{3}{*}{ Malaria is a public health threat } & Yes & 54 & 81.8 & \multirow[t]{3}{*}{0.0001} \\
\hline & & No & 10 & 15.2 & \\
\hline & & I don't know & 2 & 3.0 & \\
\hline
\end{tabular}

groups such as OVC. To the best of our knowledge, no study has evaluated knowledge about malaria transmission and access to LLINs in these individuals.

Our study showed that LLINs were the most used method for prevention of mosquito bites. This is very desirable considering the public health risk associated with the use of insecticide sprays and mosquito coils, the second most frequently used methods for controlling mosquitos. Insecticide sprays and mosquito coils pose health risks due to their toxic side effects. Their limited use in this study, however, could have been due to their high financial implication. Mosquito coils are more affordable than insecticide spray, hence, they were used more frequently. The burning of mosquito coils, however, has been reported to raise indoor carbon monoxide to a level that can cause respiratory morbidity. ${ }^{11}$ It was interesting to see that the current usage of LLINs in homes, $93.9 \%$, was higher than in other reports from Nigeria and other African countries such as
Rwanda and Sierra Leone. ${ }^{12-14}$ The peculiarity of our study population is that their limited resources to take care of malaria-related illnesses might have prompted them to take more LLINs than they need when they were distributed by the government. It appeared they made utmost use of any LLIN distribution programs, as many of the OVC households had more than one LLIN at their disposal during the study. This strategy was to rid them off of malaria for a longer period.

The fact that $89.4 \%$ of the LLINs were acquired for free is an indication of effective coverage amidst the poorest of Nigerian population. However, the fact that $38 \%$ of the individuals were not shown how to hang the nets and only about $36 \%$ were shown how to hang them by either government or health personnel is an indication that more is needed on the training aspect of hanging of LLINs. In addition, when LLINs are distributed in hospitals or primary health care centers during mass distribution campaigns, 
many public distribution centers do not prioritize training regarding hanging of the nets. When they do, the adult population usually believes that parents or guardians will teach the children how to use the LLINs. Although low, the proportion of OVC sleeping under LLINs every night (30\%) was significantly higher than the reported proportions among caregivers $(9.8 \%)$ elsewhere in Nigeria. ${ }^{6}$

Our study showed that OVC have a relatively high knowledge about the transmission of malaria. The proportion of $65.2 \%$ who knew about the route of transmission was similar to the $63.2 \%$ reported among primary school children in Bagamoyo district, Tanzania. ${ }^{15}$ Because of the limited contacts OVC have with the rest of society, their knowledge about malaria transmission could be attributed to the effort of their guardians and caregivers. However, more is needed to be done in terms of training about the transmission of the disease, as a significant number of children still fall within the 'wrong knowledge' or 'I don't know' group. High percentages of correct responses regarding the period of transmission and time of day could be due to their personal experience, corresponding to what has been observed in other population groups. Transmission of malaria is known to be high during the dry season, when there are a lot of stagnant water, providing suitable breeding sites for mosquitos, and in the night, when the female Anopheles mosquitos are more active. While a significant proportion of the study participants believed children are the group with the highest risk, their knowledge about transmission of malaria and public health impact of the disease among pregnant women seemed inadequate. This could be a result of the skewness in knowledge transfer from their guardians or caregivers. It is possible their guardians over-emphasized the public health impact of malaria in children more than in pregnant women. Overall, this study showed that the children were not at risk of malaria. This was expected, as many of the children actively utilized LLINs.

\section{CONCLUSIONS}

It appears that malaria campaign programs related to the free distribution of LLINs have a wider coverage in Ondo City, Nigeria. The utilization of LLINs among OVC may be more effective compared to the general population. The high cost of malaria management, which the caregivers of OVC could not afford, could have been responsible for this adherence to LLINs utilization. It is important that the un- derprivileged and their caregivers in Nigeria be continually integrated in malaria control programs. We recommend that this pilot study be conducted in other Nigerian locations as well, using a larger population size.

\section{CONFLICT OF INTEREST}

No potential conflict of interest was reported by the authors.

\section{ACKNOWLEDGEMENT}

We acknowledge the cooperation of the caregivers and the recruited children.

\section{REFERENCES}

1. Gallup JL, Sachs JD. The economic burden of malaria. Am J Trop Med Hyg. 2001;64:85-96.

2. World Health Organization (WHO). Malaria fact sheet No 94, 2010 April. Available from http://www.who.int/mediacentre/factsheets/fs094/en/.

3. Federal Ministry of Health $(\mathrm{FMoH})$. National Malaria and Vector Control Division. Federal Republic of Nigeria: training manual for management of malaria in Nigeria. Abuja: Federal Ministry of Health. 2008; p. 6.

4. National Population Commission (NPC) (Nigeria) and ICF International Nigeria Demographic and Health Survey 2013. Abuja, Nigeria, and Rockville, Maryland, USA

5. Okafor IP, Odeyemi KA. Use of insecticide-treated mosquito nets for children under five years in an urban area of Lagos State, Nigeria. Nig J Clin Pract. 2012;15:220-223.

6. Ibor UW, Aigbe GO, Iwara Al, Okongor OE, Okino II. Ownership and utilization of insecticide treated nets in Cross River State, Nigeria. J Med Sci. 2012;12:198-206.

7. Binka F, Indome F, Smith T. Impact of spatial distribution of permethrin impregnated bed nets on child mortality in rural northern Ghana. Amer $J$ Trop Med Hyg. 1998;59:80-85.

8. Catholic Relief Services and Catholic Secretariat of Nigeria. A situational analysis of orphans and vulnerable children in eight states of Nigeria. 2008; p. 100

9. Adaji J, Gabriel OE. Access and usage of long-lasting insecticide Nets (LLIN) in rural communities of Benue State, Nigeria. Health Sci J. 2019;13:618

10. Omonijo A, Omonijo AO. Assessment of the status of awareness, ownership, and usage of long-lasting insecticide treated nets after mass distribution in Ekiti State, Nigeria. Journal of Parasitology Research 2019;1273714

11. Salvi D, Limaye S, Muralidharan $\mathrm{V}$, et al. Indoor particulate matter $<2.5 \mu \mathrm{m}$ in mean aerodynamic diameter and carbon monoxide levels during the burning of mosquito coils and their association with respiratory health Chest. 2016;149:459-466

12. Kilian A, Lawford $\mathrm{H}$, Ujuju $\mathrm{CN}$, et al. The impact of behaviour change communication on the use of insecticide treated nets: a secondary analysis of ten post-campaign surveys from Nigeria. Malar J. 2016;15:422.

13. Kateera F, Ingabire CM, Hakizimana E, et al. Long-lasting insecticidal net source, ownership and use in the context of universal coverage: a household survey in eastern Rwanda. Malar J. 2015;14:390.

14. Gerstl S, Dunkley S, Mukhtar A, et al. Long-lasting insecticide-treated net usage in eastern Sierra Leone - The success of free distribution. Trop Med Int Health. 2010;15:480-488

15. Sumari D, Dillip A, Ndume V, Mugasa JP, Gwakisa PS. Knowledge, attitudes and practices on malaria in relation to its transmission among primary school children in Bagamoyo district, Tanzania. Malar World J. 2016;7:1-7. 